\title{
Correlation Between Nutritional Status, Cognitive Function and Daytime Sleepiness of Schoolchildren in Terengganu, Malaysia
}

\author{
Nurul Husna Rosli, Asma’ Ali, Khairil Shazmin Kamarudin, \\ Yusnita Hamzah, Hayati Mohd Yusof \\ Faculty of Fisheries and Food Science, Universiti Malaysia Terengganu, 21030 Kuala Nerus, \\ Terengganu, Malaysia
}

\begin{abstract}
This cross-sectional study aimed to determine the correlation between nutritional status, cognitive function and daytime sleepiness of schoolchildren in Kuala Nerus, Terengganu. It involved 85 schoolchildren aged 9 to 12 years. Nutritional status was determined through anthropometric measurements, biochemical analyses for hemoglobin, urinalysis and urinary iodine concentration (UIC). While cognitive performance was tested using Raven's Colored Progressive Matrices (R-CPM). The daytime sleepiness of the respondents was assessed using the Pediatric Daytime Sleepiness Scale (PDSS). It was found that $16.5 \%$ of the respondents were stunted while $4.7 \%, 12.9 \%$ and $17.7 \%$ were obese, overweight and wasted, respectively. In addition, $37.7 \%$ of the respondents were anemic and the median UIC was $177.0 \mu \mathrm{g} / \mathrm{l}$, which was categorized as normal for children. The majority $(37.6 \%)$ of the respondents had an average cognitive level. Furthermore, the mean for daytime sleepiness based on PDSS score for overall respondents was categorized under an average level that was 14.1 score. In the present research, results found that all of the factors examined in this study were not correlated with respondents' cognitive function. As the majority of the children had average to low levels of cognitive functions, it is recommended to investigate further factors associated with cognitive functions and, subsequently, to design and deliver appropriate intervention.
\end{abstract}

Keywords: cognitive function, daytime sleepiness, nutritional status, schoolchildren

\section{INTRODUCTION}

Malaysian schoolchildren face malnutrition problems, including both underweight and overweight (Zainuddin et al. 2013). Based on the latest National Health and Morbidity Survey (NHMS-2019), it was reported that $29.8 \%$ of children 5-17 years of age are overweight $(15.0 \%)$ and obese $(14.8 \%)$. A decade ago, the prevalence of overweight among children 0 to 13 years old was $5.3 \%(95 \%$ CI: $4.5-6.2)$, and of obesity $8.0 \%$ (95\% CI: 7.5-8.6). Because of the greater age range, the NHMS-2019 reported a higher proportion. The prevalence of underweight, stunting and thinness among schoolchildren in rural areas was higher than among schoolchildren in urban areas (Chung 2015; Kuay et al. 2013).

Cognitive function among primary schoolchildren might be influenced by several factors, such as gender, birth weight, children's nutritional status, parental education, household income, hemoglobin and iron status (Hamid et al. 2011). The differences in nutritional status in children may influence their food intake. For example, it is common that children that are overweight and obese are triggered to increase their daily food intake. Mental functions have biological roots, and the impairment of some neurochemical processes owing to a lack of trace elements may have mental effects. Thyroid hormones are essential for brain development and proper brain function throughout life, and iodine is required for their production (Abel et al. 2017), and its deficiency can be associated with mental retardation (Janka 2019). Furthermore, it has been reported that iodine exerts neuroprotective effects and improves intellectual performance (Martínez García et al. 2018), which includes cognitive function. The ability to cognitively control impulses may play a role in determining nutritional status, as negative moods have resulted in an increase of food intake that may

\footnotetext{
*Corresponding Author: tel: +6096684949, email: hayatimy@umt.edu.my

(Received 16-04-2021; Accepted 05-11-2021; Published 29-11-2021)
} 
lead to overweight and obesity among children (Tice et al. 2001). A study by Haile et al. (2016) found a significant correlation between heightfor-age with cognitive function among children. Height-for-age represents the accumulation of dietary deprivation over time, which may have an impact on children's academic achievement (Shariff et al. 2000).

Previous studies reported that children with low hemoglobin (less than $12 \mathrm{mg} / \mathrm{dl}$ ) had a substantially lower cognitive function score than those with normal hemoglobin (more than $12 \mathrm{mg} / \mathrm{dl}$ ) status as measured by Raven's test (Hamid et al. 2011). In terms of iodine intake, a previous study found that one third of the world's school-age population has urinary iodine below $100 \mu \mathrm{g} / \mathrm{l}$, which indicates insufficient iodine intake, while $39.9 \%$ of school-age children in South East Asia also had insufficient iodine intake (Kuay et al. 2013). Furthermore, Kuay et al. (2013) also reported that the median Urinary Iodine Concentration (UIC) of children in urban and rural areas in Terengganu was $87.7 \mu \mathrm{g} / \mathrm{l}$ and $72.4 \mu \mathrm{g} / \mathrm{l}$, respectively, which falls into the Iodine Deficiency (ID) range. Al-Mekhlafi et al. (2011) reported that children who suffered from iodine deficiency were more prone to having lower cognitive function and educational achievement than children with sufficient iodine intake.

In addition to nutritional status, previous research also suggests that daytime sleepiness can have a negative impact on students' academic performance and motivation (Abdulghani et al. 2012). Poor sleep was significantly correlated with lower performance of cognitive functions among schoolchildren (Lam et al. 2011). Sleepiness defined as individual self-reported total sleep time and daytime sleepiness are associated with poor academic achievement and other negative outcomes such as unstable mood (Drake et al. 2003). Further studies on daytime sleepiness are suggested as it may influence cognitive performance and, in particular, memory and cognitive function (Ahmad \& Bashir 2017).

Therefore, based on the knowledge acquired from previous studies regarding the malnutrition problem among children in rural Malaysia and the present of associations between nutritional status, anemia and iodine deficiencies, daytime sleepiness with cognitive function this study aimed to assess the correlations of these factors among school children in Kuala Nerus.
Hence, it can provide the latest data on factors that associated with cognitive function among schoolchildren aged 9 to 12 years old as well as baseline information regarding daytime sleepiness and cognitive function among this demography which is not widely reported in previous studies especially in Malaysia. In addition, the data gained from this study can also be used as a baseline for schoolchildren aged 9 to 12 years old in other states other than Terengganu in similar situations.

\section{METHODS}

\section{Design, location, and time}

The present study was a cross-sectional study carried out in two primary schools located in Kuala Nerus, Terengganu. Two primary schools were chosen, namely, SRI Al-Amin and SK Tanjung Gelam. The respondents were sampled in both schools within a two-month period. Ethical approval for this study was obtained from the Research, Management and Innovation Centre, Universiti Malaysia Terengganu with reference number: UMT/RMIC/2-2/62 (81).

\section{Sampling}

In the present study, convenience sampling was used. There were five primary schools that had been selected in Kuala Nerus. However, through convenience sampling, only two primary schools were chosen to be involved in this study. These schools were chosen because of easy accessibility as their headmasters were willing to cooperate by giving their permission. Besides, the respondents were available during the data collection.

The criterion for inclusion of the respondents in both schools were schoolchildren aged 9 to 12 years who were approved by their parents or guardians. This age group was chosen based on a discussion with the school administration that allowed researchers to be involved with at least 9 years of children. Information consent sheets that thoroughly explain the objectives and methodology of this study were also given to the respondents and parents along with the consent sheet. The Yamane (1967) formula was applied in order to determine the sample size of this study with a $95 \%$ confidence interval. The common margin of error used in other studies ranges from $5 \%$ to $10 \%$. Therefore, the margin of error used 
in this study was in between the range, which was $7 \%$. The size of the population of this study was 145 respondents, and on the basis of the formula, the calculated sample size was 85 respondents.

\section{Data collection}

The tools used for sampling in the present study were a questionnaire, anthropometry measurements and biochemical analyses. The questionnaire was divided into three sections: Section A contained socio-demographic information, while Section B included eight items assessing respondents' daytime sleepiness following Drake et al. (2003), whereby a higher score on the Pediatric Daytime Sleepiness Scale (PDSS) indicated greater levels of sleepiness. Lastly, Section C was the cognitive function test, with 36 matrices of diagrammatic puzzles of Raven's Colored Progressive Matrices (R-CPM) (Raven 2008).

Anthropometry data used for this study included body height, body weight and BMI. In this study, weight was measured using a Tanita digital body fat monitor/scale UM-026 (Tanita, UK). Body height measurements were also taken without shoes and socks (SECA, Germany). The weight and the height were measured to the nearest $0.1 \mathrm{~kg}$ and $0.1 \mathrm{~cm}$, respectively (Hamid et al. 2011). Height-for-age was then categorized as tall, normal, stunted, and severe stunted while BMI-for-age was classified as obesity, overweight, normal, thin, and severe thin (WHO 2007). The WHO AnthroPlus version 1.0.3 was used to determine $\mathrm{Z}$-scores for height-for-age and BMI-for-age among children.

In terms of biochemical analysis, the instrument used for testing hemoglobin concentration was a photometer called HemoCue ${ }^{\circledR}$. The urinalysis was performed by using the Urine Analyzer PocketChem ${ }^{\mathrm{TM}}$ UA PU-4010 in order to determine the presence of bilirubin, blood, glucose, ketone, leukocyte, nitrite, $\mathrm{pH}$, protein, specific gravity and urobilinogen. Only a small amount of the mid-stream of urine was needed for the test. The laboratory procedure widely used to determine the concentration of urinary iodine is based on the Sandell-Kolthoff reaction (Jooste \& Strydom 2010).

\section{Data analysis}

In the present study, the Statistical Package for Social Sciences (SPSS version 20.0) was used to analyze the data. Spearman's Rank Order Correlation was used for non-parametric test to measure the relationship between the parameters of the test. In all analyses, $\mathrm{p}<0.05$ was used to indicate significant outcomes.

\section{RESULTS AND DISCUSSION}

Table 1 shows the socio-demographic characteristics of children. The majority (45.9\%) of respondents were aged 11 years old, all from Malay families. More than half of the children live in households that consist of four to six people. In terms of parents' employment status, most of their fathers $(92.9 \%)$ were working and more than half of mothers $(67.1 \%)$ were also working.

\section{Nutritional status based on anthropometric measurement}

Table 2 presents the mean height, body weight, BMI-for-age and height-for-age of the children. In terms of BMI-for-age, the majority of the respondents $(56.5 \%)$ were in normal condition, while $4.7 \%, 12.9 \%, 10.6 \%$, and $7.1 \%$ were obese, overweight, wasted and severely wasted, respectively. On the other hands, majority $(83.5 \%)$ of the respondents had normal heightfor-age while $9.4 \%$ and $7.1 \%$ were stunted and severely stunted, respectively.

As stunting reflects past nutrition, during their early childhood, some of these children might have experienced poor food intake and had some sort of infection (Zainuddin et al. 2013). In addition, they probably were consistently living in an unchanged situation due to underprivileged living conditions (Shariff et al. 2000). Picauly \& Toy (2013) reported that the malnutrition conditions, such as stunting, experienced by school-age children will affect their ability to learn in school and, subsequently, may affect their learning achievement. Besides, it has been reported that children's sex and age affect both wasted and stunted. With increasing age, they are more prone to stunting but without wasting (Shariff et al. 2000).

\section{Nutritional status based on biochemical analysis}

In the present study, the majority $(62.35 \%)$ of the respondents had a normal reading of hemoglobin concentration, while more than one third of the respondents were anemic. Ngui et al. 
Rosli et al.

Table 1. Socio-demographic characteristics of respondents

\begin{tabular}{|c|c|c|}
\hline Characteristics & $\mathrm{n}=85$ & $\%$ \\
\hline \multicolumn{3}{|l|}{ Gender } \\
\hline Boy & 46 & 54.1 \\
\hline Girl & 39 & 45.9 \\
\hline \multicolumn{3}{|l|}{ Age of child (years old) } \\
\hline 9 & 15 & 17.6 \\
\hline 10 & 12 & 14.1 \\
\hline 11 & 39 & 45.9 \\
\hline 12 & 19 & 22.4 \\
\hline \multicolumn{3}{|l|}{ Median (IQR): 11 (1) } \\
\hline \multicolumn{3}{|l|}{ Race } \\
\hline Malay & 85 & 100 \\
\hline \multicolumn{3}{|c|}{ Number of family members (including parents) } \\
\hline $1-3$ & 3 & 3.5 \\
\hline $4-6$ & 45 & 52.9 \\
\hline $7-9$ & 36 & 42.4 \\
\hline$\geq 10$ & 1 & 1.2 \\
\hline \multicolumn{3}{|l|}{ Range: $1-10$} \\
\hline \multicolumn{3}{|l|}{ Median (IQR): 2 (1) } \\
\hline \multicolumn{3}{|l|}{ Employment status of father } \\
\hline Working & 79 & 92.9 \\
\hline Not working & 6 & 7.1 \\
\hline \multicolumn{3}{|l|}{ Employment status of mother } \\
\hline Working & 57 & 67.1 \\
\hline Not working & 28 & 32.9 \\
\hline
\end{tabular}

(2012) reported that anemia among adolescent is caused by physiological iron losses during menstrual bleeding in female and increased iron needs during the growth spur period.

Based on Table 3, the overall median UIC of respondents was $177.0 \mu \mathrm{g} / 1$, which was categorized as a normal UIC for children. In general, this reflects that the children had sufficient iodine intake in their daily food intake. According to the study by Selamat et al. (2010) in different locations, the median UIC of children aged eight to ten years was in the normal range, in terms of Malaysian data $(109 \mu \mathrm{g} / \mathrm{l})$, and data for Peninsular Malaysia $(104 \mu \mathrm{g} / \mathrm{l})$, Sabah $(150 \mu \mathrm{g} / \mathrm{l})$ and Sarawak $(102 \mu \mathrm{g} / \mathrm{l})$. A mandatory Universal Salt Iodization (USI) has been implemented in Sarawak, Malaysia since 2008. Recently, Kuay et al. 2021 reported the overall median Urinary Iodine Concentration (UIC) level among the school-aged children in Sarawak was $126.0 \mu \mathrm{g} / \mathrm{l}$ (Interquartile Range (IQR): 71.0-200.9 $\mu \mathrm{g} / \mathrm{l}$ ) and classified as adequate iodine status.

In the present study, the median UIC for children in Terengganu $(177.0 \mu \mathrm{g} / \mathrm{l})$ was higher compared with the other regions, as stated above. The reason for acceptable UIC among schoolchildren in Terengganu might be due to the availability of iodine rich food sources to 
Nutritional status, cognitive function and daytime sleepiness of schoolchildren

Table 2. Anthropometric measurements and growth status of respondents

\begin{tabular}{lc}
\hline \multicolumn{1}{c}{ Parameter } & $\begin{array}{c}\text { Overall } \\
(\mathrm{n}=85)\end{array}$ \\
\hline Height $(\mathrm{cm})$ & $140.50 \pm 8.08$ \\
Weight $(\mathrm{kg})$ & $35.73 \pm 10.72$ \\
BMI-for-age & \\
Normal & $48(56.5 \%)$ \\
Obese & $4(4.7 \%)$ \\
Overweight & $11(12.9 \%)$ \\
Possible risk of overweight & $7(8.2 \%)$ \\
Wasted & $9(10.6 \%)$ \\
Severely wasted & $6(7.1 \%)$ \\
Height-for-age & \\
Normal & $71(83.5 \%)$ \\
Stunted & $8(9.4 \%)$ \\
Severely stunted & $6(7.1 \%)$ \\
\hline
\end{tabular}

"BMI: Body Mass Index

Table 3. Hemoglobin and urinary iodine concentration

\begin{tabular}{lcc}
\hline \multicolumn{1}{c}{ Indicators } & $\begin{array}{c}\text { Overall } \\
(\mathrm{n}=85)\end{array}$ & Range \\
\hline $\begin{array}{l}\text { Hemoglobin } \\
\text { concentration }(\mathrm{g} / \mathrm{dl})\end{array}$ & $12.00 \pm 1.50$ & $6.00-15.80$ \\
Normal & $53(62.35 \%)$ & \\
Anemic & $32(37.65 \%)$ \\
& $32(37.65 \%)$ & $24-245$ \\
$\begin{array}{l}\text { Urinary iodine } \\
\text { concentration }(\mu \mathrm{g} / \mathrm{l})\end{array}$ \\
\hline Data are presented as mean $\pm \mathrm{SD}$ or median (IQR)
\end{tabular}

Data are presented as mean \pm SD or median (IQR) residents of the community, resulting in a higher frequency of iodine food consumption and a lower risk of iodine deficiency. A study by Kuay et al. (2013) showed that the median UIC of children who lived in urban areas in Terengganu was $87.7 \mu \mathrm{g} / \mathrm{l}$, which falls into the iodine deficiency range. However, in the present study, the median UIC of children who lived in Terengganu was categorized as a normal UIC for children. Thus, the consumption of iodine among children in this state has improved over the last five-year period.

In terms of urinalysis, all of the respondents had no glucose in their urine. The majority $(98.82 \%)$ of respondents had no protein in their urine. According to Simmerville et al. (2005), protein is not normally found in urine, as most proteins are too big to diffuse out of the glomerular filtrate. All of the respondents had normal urine $\mathrm{pH}$, which was between 4.5 to 8.0 and this indicates that the respondents did not have UTI or calculi. Furthermore, the majority of the respondents $(76.47 \%)$ had normal Urinary Specific Gravity (USG) and for some respondents that showed high USG, they might be suffering from dehydration due to inadequate fluid intake in school. Some of the factors that raise specific gravity include dehydration, diarrhea, emesis, UTI and proteinuria as well as water restriction (Simmerville et al. 2005). However, $16.47 \%$ of the respondents showed positive blood results in their urine. The abnormal blood found in urine among male respondents might be due to infection, whereas positive blood results among female respondents were probably because they were undergoing menstruation when the test was carried out. Lastly, the majority $(96.47 \%)$ of respondents had negative leukocyte esterase in their urine, while those who showed positive results were suspected of having an infection.

\section{Raven cognitive function}

As shown in Table 4, the majority (37.6\%) of the respondents had an average cognitive level, followed by high average, low average and extremely low cognitive levels with $25.9 \%, 12.9 \%$ and $10.6 \%$, respectively. The mean R-CPM score for overall respondents was 93.5 , in the range of 9.0 to 135.0 of total scores. The R-CPM test depends on non-verbal logical reasoning.

In addition, a recent study reported that varied improvements in cognitive skills (as 
Rosli et al.

Table 4. Cognitive function level of respondents

\begin{tabular}{lccc}
\hline \multicolumn{1}{c}{ Parameter } & Overall $(\mathrm{n}=85)$ & Mean score & Range score \\
\hline Cognitive function level & & $93.5 \pm 20.2$ & $9-135$ \\
Extremely low & $9(10.6 \%)$ & & \\
Borderline & $8(9.4 \%)$ & & \\
Low average & $11(12.9 \%)$ & \\
Average & $32(37.6 \%)$ & \\
High average & $22(25.9 \%)$ & \\
Superior & $2(2.4 \%)$ & \\
Very superior & $1(1.2 \%)$ & \\
\hline
\end{tabular}

measured using R-CPM) were observed for different variables in both the intervention and control groups of preschool children with no robust evidence for physical activity-interventionrelated improvements (Jaksic et al. 2020).

\section{Daytime sleepiness}

Daytime sleepiness, including sleep continuity, how rested an individual feels upon waking up, and how alert one is during the day, has an important effect on educational outcomes in children (Blunden et al. 2018). In addition, sleep can also affect young adolescents' mental, social, physical and psychological components (Blunden et al. 2018). However, lack of sleep time and daytime sleepiness among schoolaged children were linked with low scores in neuropsychological attention studies (Zainuddin et al. 2013). A meta-analysis investigating the effects of school start times on sleep and daytime sleepiness has discovered that later school start times result in longer sleep durations and reduced daytime sleepiness in adolescents (Bowers \& Moyer 2017). In a systematic review, Meyer et al. (2017) found a moderate use of the Paediatric Daytime Sleepiness Scale (PDSS) to assess daytime sleepiness. This tool provides for the tracking of factors that influence children's and adolescents' excessive daytime drowsiness. The mean score for daytime sleepiness based on the (PDSS) for overall respondents was 14.1 with a range of 5 to 25 scores. It was categorized under average level scores. On the other hand, higher PDSS scores indicate a higher level of sleepiness associated with the individual's total sleep time (Drake et al. 2003). Based on a study by Drake et al. (2003), the mean score PDSS for overall respondents was 15.3 , almost similar to the mean score of the present study, which was at 14.1. Another study by Perez-Chada et al. (2007) reported that the PDSS (mean score: 15.7) was robustly and significantly associated with academic failure.

\section{Correlation between nutritional status and daytime sleepiness with cognitive function among respondents}

The present study found no significant correlation between height-for-age and BMIfor-age with cognitive function. The results also demonstrated no significant correlations between hemoglobin and urinary iodine concentration with cognitive function. Lastly, there was also no significant correlation between daytime sleepiness and cognitive function, as shown in Table 5.

These findings are in agreement with a study by Hamid et al. (2011) that reported heightfor-age z-scores are not apparently correlated with cognitive tests. In contrast, Haile et al. (2016) found a significant correlation $(\mathrm{r}=0.38$; $\mathrm{p}=0.001$ ) between children's height-for-age and cognitive function. Another study also reported that brain functions including cognition, memory and locomotors skills are influenced by undernutrition (Ranade et al. 2008). A study by Haile 


\section{Nutritional status, cognitive function and daytime sleepiness of schoolchildren}

Table 5. Correlation between nutritional status and daytime sleepiness with cognitive function

\begin{tabular}{lcc}
\hline \multirow{1}{*}{ Parameter } & \multicolumn{2}{c}{$\begin{array}{c}\text { Cognitive } \\
\text { function }\end{array}$} \\
\cline { 2 - 3 } & $\mathrm{r}$ & $\mathrm{p}$ \\
\hline BMI-for-age & -0.116 & 0.292 \\
Height-for-age & -0.021 & 0.850 \\
Hemoglobin concentration & -0.170 & 0.120 \\
Urinary iodine concentration & 0.076 & 0.489 \\
Daytime sleepiness & -0.017 & 0.876 \\
\hline
\end{tabular}

"BMI: Body Mass Index

et al. (2016) reported no significant correlation between BMI-for-age with cognition, similar to the present findings.

In contrast, a study by Hamid et al. (2011) reported that hemoglobin concentration was significantly correlated with cognitive function $(\mathrm{r}=0.19 ; \mathrm{p}=0.006)$. In their findings, it was reported that children with iron deficiency had significantly lower cognitive function test scores than their normal hemoglobin counterparts (Hamid et al. 2011). Another study by Al-Mekhlafi et al. (2011) among children in rural areas revealed that those suffering from iron deficiency anemia were more prone to having lower cognitive function and academic performance than healthy children. Across past studies, it has been conclusively reported that iron deficiency anemia delays the psychomotor development and impairs the cognitive scores of pre-school and school-age children in Thailand, Indonesia and Zaire (AlMekhlafi et al. 2011). Several studies have linked iron deficiency anemia to cognitive impairment, psychomotor disorders, and behavioral problems in children of all ages. Disorders of attention, emotion, intelligence, and sensory perception are the most common cognitive functions impaired by iron deficiency. These long-term impacts can have a negative impact on learning ability and professional ability acquisition (Radlowski \& Johnson 2013; Jáuregui-Lobera 2014).

Despite the well-documented importance of adequate iodine intake for early-life neurodevelopment, Kippler et al. (2016) found no association between the mothers' urinary iodine concentration (median $172 \mu \mathrm{g} / \mathrm{l}$ ) and children's general cognitive score, even when comparing children born to mothers with an inadequate iodine status (urinary concentrations less than $150 \mu \mathrm{g} / \mathrm{l})(36 \%$ of the women) to those born to mothers with an adequate iodine status (urinary iodine concentration of more than $150 \mu \mathrm{g} / \mathrm{l})$. This might be due to the iodine deficit that was discovered was not be frequent or severe enough to impact neurodevelopment.

The present study also shows no correlation between daytime sleepiness and cognitive function. This finding also was not in agreement with Lam et al. (2011), who reported that daytime sleepiness was significantly correlated with cognitive function among schoolchildren. Another study by Moreau et al. (2013) also reported that lack of sleeping time among school-aged children is associated with lower performance on neuropsychological tests of attention. Drake et al. (2003) stated that sleepiness would be related to individual total sleep time and quality that would be associated with poor academic achievement and other negative outcomes, such as poor mood.

\section{CONCLUSION}

In conclusion, the majority of the respondents had normal growth for both the indicators of height-for-age and BMI-forage. Based on urinary iodine analysis, the results indicate that they received sufficient micronutrients such as iodine in their daily food intake. The majority of them had average cognitive function levels. In the present study, there was no significant correlation $(p>0.05)$ between anthropometric indices (height-for-age and BMI-for-age), hemoglobin concentration, urinary iodine concentration and daytime sleepiness with children's cognitive function.

The present study provides the latest data about the correlation between nutritional status, daytime sleepiness and cognitive function among schoolchildren in Kuala Nerus. This data is useful for future reference, especially the data about daytime sleepiness, as it was not widely investigated in the previous studies especially in Malaysia. As the majority of the children had average to low levels of cognitive functions, it 
is recommended to investigate further factors associated with cognitive functions and, subsequently, to design and deliver appropriate intervention.

\section{ACKNOWLEDGEMENT}

The authors would like to express their sincere gratitude to all the respondents for their participation, full co-operation and patience during the study. This study was funded by the School of Food Science and Technology, Universiti Malaysia Terengganu (UMT).

\section{DECLARATION OF INTERESTS}

The authors confirm that there are no known conflicts of interest associated with this publication.

\section{REFERENCES}

Abel MH, Ystrom E, Caspersen I, Meltzer H, Aase H, Torheim LE, Askeland RB, Reichborn-Kjennerud T, Brantsæter AL. 2017. Maternal iodine intake and offspring attention-deficit/hyperactivity disorder: Results from a large prospective cohort study. Nutrients 9(11):1239. https://doi. org/10.3390/nu9111239

Abdulghani HM, Alrowais NA, Bin-Saad NS, Al-Subaie NM, Haji AMA, Alhaqwi AI. 2012. Sleep disorder among medical students: Relationship to their academic performance. Med Teach 34(Suppl 1):S37-S41. https://doi.org/10.3109/0142 159X.2012.656749

Ahmad S, Bashir S. 2017. A pilot study investigating the association between sleep and cognitive function among adolescents. Asian J Psychiatr 28:34-37. https://doi. org/10.1016/j.ajp.2017.03.020

Al-Mekhlafi HM, Mahdy MA, Sallam AA, Ariffin WA, Al-Mekhlafi AM, Amran AA, Surin J. 2011. Nutritional and socio-economic determinants of cognitive function and educational achievement of aboriginal schoolchildren in rural Malaysia. $\mathrm{Br}$ J Nutr 106(7):1100-1106. https://doi. org/10.1017/S0007114511001449

Blunden S, Magee C, Attard K, Clarkson L, Caputi P, Skinner T. 2018. Sleep schedules and school performance in Indigenous Australian children. Sleep health 4(2):135-140. https://doi.org/10.1016/j. sleh.2017.12.006

Bowers JM, Moyer A. 2017. Effects of school start time on students' sleep duration, daytime sleepiness, and attendance: A meta-analysis. Sleep Health 3(6):423-431. https://doi.org/10.1016/j.sleh.2017.08.004

Chung S. 2015. Body mass index and body composition scaling to height in children and adolescent. Ann Pediatr Endocrinol Metab 20(3):125-129. https://doi. org/10.6065/apem.2015.20.3.125

Drake C, Nickel C, Burduvali E, Roth T, Jefferson C, Pietro B. 2003. The pediatric daytime sleepiness scale (PDSS): Sleep habits and school outcomes in middle-school children. Sleep 26(4):455-458. https://doi. org/10.1037/t02761-000

Haile D, Gashaw K, Nigatu D, Demelash H. 2016. Cognitive function and associated factors among school age children in Goba Town, South-East Ethiopia. Cogn Dev 40:144-151. https://doi.org/10.1016/j. cogdev.2016.09.002

Hamid JJM, Amal MK, Hasmiza H, Pim CD, $\mathrm{Ng}$ LO, Wan MWM 2011. Effect of gender and nutritional status on academic achievement and cognitive function among primary school children in a rural district in Malaysia. Malays J Nutr 17:189-200.

Jaksic D, Mandic S, Maksimovic N, Milosevic Z, Roklicer R, Vukovic J, Pocek S, Lakicevic N, Bianco A, Cassar S et al. 2020. Effects of a nine-month physical activity intervention on morphological characteristics and motor and cognitive skills of preschool children. Int J Environ Res Public Health 17(18):6609. https:// doi.org/10.3390/ijerph17186609

Janka Z. 2019. Tracing trace elements in mental functions. Ideggyogy $\mathrm{Sz}$ 30:72(11-12):367-379. https://doi. org/10.18071/isz.72.0367

Jáuregui-Lobera I. 2014. Iron deficiency and cognitive functions. Neuropsychiatr Dis Treat 10:2087-2095. https://doi. org/10.2147/NDT.S72491

Jooste PL, Strydom E. 2010. Methods for determination of iodine in urine and salt. Best Pract Res Clin Endocrinol Metab 
Nutritional status, cognitive function and daytime sleepiness of schoolchildren

24:77-88. $\quad$ https://doi.org/10.1016/j. beem.2009.08.006

Kippler M, Bottai M, Georgiou V, Koutra K, Chalkiadaki G, Kampouri M, Kyriklaki A, Vafeiadi M, Fthenou E, Vassilaki M et al. 2016. Impact of prenatal exposure to cadmium on cognitive development at preschool age and the importance of selenium and iodine. Eur $\mathrm{J}$ Epidemiol 31(11):1123-1134. https://doi. org/10.1007/s10654-016-0151-9

Kuay LK, Ying CY, Zainuddin AA, Huey TC, Selamat R, Cheong KC, Ismail H, Hock LK. 2013. Inadequate iodine intake among school children in Terengganu-findings from the national iodine deficiency disorder survey 2008. Int J Public Health Res 3(1):198-203.

Kuay LK, Chin TB, Ying CY, Hussain H, Mahmud NA, Kassim MSA, Harith AA, Man CS, Salleh R, Aris T. 2021. Pregnant women are iodine deficient while schoolaged children demonstrate adequate iodine status in Sarawak, Malaysia. Food Nutr Bull 42(3):406-413. https://doi. org/10.1177/03795721211002079

Lam JC, Mahone EM, Mason TB, Scharf SM. 2011. The effects of napping on cognitive function in preschoolers. J Dev Behav Pediatr 32(2):90-97. https://doi. org/10.1097/DBP.0b013e318207ecc7

Martínez García RM, Jiménez Ortega AI, López Sobaler AM, Ortega RM. 2018. Nutrition strategies that improve cognitive function. Nutr Hosp 7:35(Spec No6):16-19. https:// doi.org/10.20960/nh.2281

Meyer C, Ferrari GJ, Barbosa DG, Andrade RD, Pelegrini A, Felden ÉPG. 2017. Analysis of daytime sleepiness in adolescents by the pediatric daytime sleepiness scale: A systematic review. Rev Paul Pediatr 35(3):351-360. https://doi. org/10.1590/1984-0462/;2017;35;3;00015

Moreau V, Rouleau N, Morin C. 2013. Sleep, attention, and executive functioning in children with attention-deficit/ hyperactivity disorder. Arch Clin Neuropsychol 28(7):692-699. https://doi. org/10.1093/arclin/act051

National Health Morbidity Survey 2019. 2019. Fact Sheet. https://iku.moh.gov. my/images/IKU/Document/REPORT/
NHMS2019/Fact_Sheet_NHMS_2019English.pdf [Accessed September 15th 2021].

Ngui R, Lim YAL, Chong Kin K, Sek Chuen C, Jaffar S. 2012. Association between anaemia, iron deficiency anaemia, neglected parasitic infections and socioeconomic factors in rural children of West Malaysia. Plos Negl Trop Dis 6(3):e1550. https://doi.org/10.1371/ journal.pntd.0001550

Perez-Chada D, Perez-Lloret S, Videla AJ, Cardinali D, Bergna MA, FernándezAcquier M, Larrateguy L, Zabert GE, Drake C. 2007. Sleep disordered breathing and daytime sleepiness are associated with poor academic performance in teenagers. A study using the pediatric daytime sleepiness scale (PDSS). Sleep 30(12):1698-1703. https://doi.org/10.1093/sleep/30.12.1698

Picauly I, Toy SM. 2013. The determinant analysis and the impact of stunting for school children school performance in Kupang and Sumba Timur, NTT. J Gizi Pangan 8(1):55-62. https://doi.org/10.25182/ jgp.2013.8.1.55-62

Radlowski EC, Johnson RW. 2013. Perinatal iron deficiency and neurocognitive development. Front Hum Neurosci 7:585. https://doi.org/10.3389/fnhum.2013.00585

Ranade SC, Rose A, Rao M, Gallego J, Gressens P, Mani S. 2008. Different types of nutritional deficiencies affect different domains of spatial memory function checked in a radial arm maze. Neurosc 152(4): 859-866. https://doi.org/10.1016/j. neuroscience. 2008.01 .002

Raven J. 2008. Coloured Progressive Matrices and Crichton Vocabulary Scale Manual. London (UK): Pearson Education.

Selamat R, Wan Mohamud WN, Zainuddin AA, Che Abdul Rahim NS, Ghaffar SA, Aris T. 2010. Iodine deficiency status and iodised salt consumption in Malaysia: Findings from a national iodine deficiency disorders survey. Asia Pac J Clin Nutr 19(4):578-585. https://search.informit. org/doi/10.3316/ielapa.632105898577197

Shariff ZM, Bond JT, Johson NE. 2000. Nutritional status of primary school children from low income households in Kuala Lumpur. Malays J Nutr 6(1):17-32. 
Simmerville JA, Maxted WC, Pahira JJ. 2005. Urinalysis: A comprehensive review. Am Fam Physician 71(6):1153-1162.

Tice DM, Bratslavsky E, Baumeister RF. 2001. Emotional distress regulation takes precedence over impulse control: If you feel bad, do it! J Pers Soc Psychol 80(1):53-67. https://doi.org/10.1037/0022-3514.80.1.53

[WHO] World Health Organization. 2007. Growth Chart for Children 5-19 years. http://www. who.int/growthref/en [Accessed April 23rd 2018].

Yamane T. 1967. Statistics, an Introductory Analysis. 2nd ed. New York (USA): Harper and Row.

Zainuddin AA, Selamat R, Baharudin A, Ghaffar SA, Rahim NCA, Aris T. 2013. Nutritional status of Malaysian primary school children aged 8-10 years: Findings from the 2008 National IDD Survey. Malays J Nutr 19(2):149-161. 